\title{
CYTOPATHOLOGICAL ANALYSIS OF UNGUIDED TRANSTHORACIC FINE NEEDLE ASPIRATION CYTOLOGY AND ITS UTILITY IN DIAGNOSIS
}

\author{
Kausalya Kumari Sahu, Ramesh Chandra Sahoo², Pooja Kundapur Suresh ${ }^{3}$, C. Vasudeva Raghuveer, \\ Sridevi Hanaganahalli Basavaiah ${ }^{5}$
}

1 Professor, Department of Pathology, Kasturba Medical College, Mangalore, Manipal Academy of Higher Education. 2Professor, Department of Chest Disease and Allergy, Kasturba Medical College, Attavar, Mangalore, Manipal Academy of Higher Education.

${ }^{3}$ Associate Professor, Department of Pathology, Kasturba Medical College, Mangalore, Manipal Academy of Higher Education. ${ }^{4}$ Professor, Department of Pathology, Sri Devaraj Urs Medical College, Kolar.

${ }^{5}$ Associate Professor, Department of Pathology, Kasturba Medical College, Mangalore, Manipal Academy of Higher Education.

\begin{tabular}{l}
\hline ABSTRACT \\
FACKGROUND \\
Fine needle aspiration cytology (FNAC) is a well-accepted and safe diagnostic procedure for the superficial lesions of the body; \\
however, it can also be used for intrathoracic lesions with or without radiological guidance. \\
The objective is to study the utility of unguided transthoracic FNAC as a diagnostic aid in intrathoracic lesions.
\end{tabular}

\section{MATERIALS AND METHODS}

This descriptive study of one hundred and fifteen cases of intrathoracic lesions presenting as pulmonary nodules was done by unguided transthoracic fine needle aspiration cytology (TFNAC) to assess the diagnostic accuracy.

\section{RESULTS}

The yield was diagnostic in 76 cases. Among the 76 cases, 64 cases were malignant le sions \& 12 were non-neoplastic. There were no false positives; however, 5 cases showed false negative reports. The sensitivity, specificity and positive predictive value were $90.1 \%$, $100 \%$ and $100 \%$ respectively. Minimal complications were encountered like pain at the punctured site, blood-tinged sputum and pneumothorax in two cases.

\section{CONCLUSION}

Unguided TFNAC is a simple, dependable and economical procedure for the diagnosis of peripheral lung lesions.

\section{KEYWORDS}

Transthoracic, Fine Needle Aspiration Cytology, Intrathoracic Lesions.

HOW TO CITE THIS ARTICLE: Sahu KK, Sahoo RC, Suresh PK, et al. Cytopathological analysis of unguided transthoracic fine needle aspiration cytology and its utility in diagnosis. J. Evolution Med. Dent. Sci. 2017;6(95):6940-6942, DOI: 10.14260/jemds/2017/1506

\section{BACKGROUND}

Bronchogenic carcinoma is the most fatal carcinoma in the world and is increasing in incidence day by day. Together with metastatic malignancies and inflammatory lesions it poses a diagnostic dilemma to the clinician. ${ }^{1}$

There are a number of diagnostic techniques for the evaluation of intrathoracic lesions starting from plain X-ray to computerised tomography (CT) and the material for diagnosis can be obtained by fine needle aspiration cytology to thick needle biopsy. Mostly central lesions are diagnosed by fibreoptic bronchoscope \& peripheral lesions by thick needle biopsy. Percutaneous transthoracic fine needle aspiration cytology (PTFNAC) of the lung as a diagnostic method has gained increasing acceptance in the recent years. Fine needle aspiration technique is a well-known, safe technique used in the evaluation of intrathoracic lesions. It has been used in the

'Financial or Other Competing Interest': None.

Submission 22-09-2017, Peer Review 17-10-2017,

Acceptance 23-10-2017, Published 23-12-2017.

Corresponding Author:

Dr. Pooja Kundapur Suresh,

Associate Professor

Department of Pathology,

Kasturba Medical College,

Lighthouse Hill Road, Mangalore,

Manipal Academy of Higher Education.

E-mail:puja4444@gmail.com

DOI: $10.14260 /$ jemds $/ 2017 / 1506$

\section{(c) (1) (3) $\Theta$}

diagnosis of intrathoracic lesions for over hundred years. The aspiration cytology will lead to an early diagnosis and initiation of treatment.

The history of FNAC lung dates back to the 19th century when Heyden \& Menetrier introduced the technique of lung puncture for the identification of microbes and malignant cells. The use of thick needle biopsy led to complications like pneumonia. In 1886, Menetrier had first diagnosed lung cancer by needle biopsy. But because of fear of serious complications; this did not gain popularity. In 1960s, Nordenstrom revitalised the aspiration technique using thin needle (18-19 gauge) with low incidence of complications and increased diagnostic yield with the use of biplane fluoroscopy and image intensification, ultrasound and computerised tomography (CT). ${ }^{1-3}$ However, main prohibitive factors are the radiation hazards of CT scans, localisation problems in ultrasound, cost factor of the procedure, and the peripheral health centres undermine their utility. ${ }^{1}$ Thus, the unguided transthoracic fine needle aspiration basing on clinical and chest radiograph finding can be used.1-3 This study was conducted to retrieve the usefulness of unguided TFNAC in the present era.

\section{MATERIALS AND METHODS}

A descriptive study of cases who had clinical \& radiological evidence of intrathoracic lesions for a period of 2 years were included in the study. An informed consent was obtained from 
all the patients. Bleeding time \& clotting time was performed prior to aspiration. TFNAC was performed by a pulmonologist using a 20- gauge spinal needle attached to simple $10 \mathrm{cc}$ disposable suction syringe after localisation the lesion. The depth of the lesion was determined by posteroanterior and lateral radiography. No local anaesthesia was given. Upon retraction of the piston, the needle was moved to and fro in the same direction to minimise or to avoid more trauma to the normal lung parenchyma. The aspirated material was stained with routine Papanicolaou stain on methanol fixed smears, and May-Grunwald-Giemsa (MGG) stain on air dried smears. Apart from these routine stains, special stains like periodic acid Schiff (PAS), Mucicarmine, Acid fast bacilli (AFB) stain were done according to requirement. The stained slides were evaluated by the cytopathologists for the following features: adequacy of material; normal structures; cellularity and arrangement of cells; predominant cell type; cytoplasmic and nuclear features; cellular and nuclear pleomorphism; nuclear atypia; intranuclear inclusions; background necrosis, inflammation; presence of any other organism \& fungus. In clinically suspected inflammatory lesions, and whenever aspirated material was like pus the material was sent for culture sensitivity and AFB culture. After the aspiration, the patient was kept under observation for 24 hours. All analyses were performed using IBM SPSS Statistics software. The data were analysed by inserting the data in tabular columns and calculating the mean, median, range, sensitivity \& specificity. The study was cleared by institutional ethics committee.

\section{RESULTS}

During the study period, 115 cases of intrathoracic lesions were subjected to TFNAC. The age of the patients ranged from 20 to 82 years with average age being 55 years. The maximum number of patients were noted in 51-60 years age group. The male: female ratio was 7:1. The diagnostic yield was provided in 76 cases $(66 \%)$. As histopathology is the gold standard, these were correlated with histopathology. Although histopathological correlation was available in 63 cases, the tissue was adequate in 46 cases. Out of 46 cases, 9 were nonneoplastic \& 37 were neoplastic including secondaries. The cytological diagnosis and histological correlation are summarised in Table 1. There was no false positive diagnosis, but five cases showed false negative diagnosis. The sensitivity, specificity, positive predictive value \& negative predictive value were $91 \%, 100 \%, 100 \%$ and $20 \%$ respectively. Of the neoplastic lesions, squamous cell carcinoma was the commonest followed by adenocarcinoma, small cell carcinoma, poorly differentiated carcinoma, large cell \& bronchoalveolar carcinoma. We found two cases of tuberculosis which showed caseous necrosis, epithelioid granulomas with Langhans giant cells \& AFB positivity. Fungal infection such as aspergilloma was difficult to diagnose on cytology; however, it was diagnosed on histopathology by special stain \& microbiology by culture.

Two patients had minor complications like pneumothorax and blood-tinged sputum which was managed conservatively.

\begin{tabular}{|c|c|c|}
\hline Diagnosis & $\begin{array}{c}\text { Cytological } \\
\text { Diagnosis in 76 } \\
\text { Cases }\end{array}$ & $\begin{array}{c}\text { Histological } \\
\text { Diagnosis in 46 } \\
\text { Cases }\end{array}$ \\
\hline Non-neoplastic & $(12)$ & $(9)$ \\
\hline Inflammatory & 6 & 6 \\
\hline
\end{tabular}

\begin{tabular}{|c|c|c|}
\hline Tuberculosis & 2 & 2 \\
\hline Aspergilloma & 0 & 1 \\
\hline Abscess & 2 & 0 \\
\hline $\begin{array}{l}\text { Pleuropulmonary } \\
\text { fibrosis }\end{array}$ & 2 & 0 \\
\hline $\begin{array}{c}\text { Neoplastic } \\
\text { Primary } \\
\text { Malignant }\end{array}$ & (63) & (36) \\
\hline $\begin{array}{c}\text { Peripheral } \\
\text { carcinoid }\end{array}$ & 1 & 1 \\
\hline $\begin{array}{l}\text { Squamous cell } \\
\text { carcinoma }\end{array}$ & 19 & 13 \\
\hline Adenocarcinoma & 17 & 9 \\
\hline $\begin{array}{c}\text { Small cell } \\
\text { carcinoma }\end{array}$ & 8 & 7 \\
\hline $\begin{array}{c}\text { Large cell } \\
\text { carcinoma }\end{array}$ & 5 & 3 \\
\hline $\begin{array}{c}\text { Bronchoalveolar } \\
\text { carcinoma }\end{array}$ & 3 & 1 \\
\hline $\begin{array}{c}\text { Unclassified } \\
\text { carcinoma }\end{array}$ & 9 & 2 \\
\hline $\begin{array}{c}\text { Adenosquamous } \\
\text { carcinoma }\end{array}$ & 1 & 0 \\
\hline Secondaries & (1) & (1) \\
\hline $\begin{array}{c}\text { Extraskeletal } \\
\text { Ewing's sarcoma }\end{array}$ & 1 & 1 \\
\hline
\end{tabular}

Table 1. Cytohistopathological Correlation of Lung Lesions

\section{DISCUSSION}

Bronchogenic carcinoma is the most common visceral malignancy in men. The incidence of bronchogenic carcinoma is dramatically increasing in women. It alone accounts for approximately one third of all cancer deaths in men and $7 \%$ of all deaths in both sexes. Overall, lung cancer is the most frequent fatal malignancy.1,2

The radiographic detection of an unexpected pulmonary abnormality often poses a difficult diagnostic dilemma, particularly if the lung lesion cannot be related to any past or current illness. This is true for both focal and disseminated pulmonary diseases. ${ }^{2}$

Aspiration biopsy provides a highly accurate diagnostic method, which can be performed rapidly and with minimal risk. It provides a definitive diagnosis in most patients at low cost, with minimal trauma. Patients who are clinically inoperable can receive appropriate chemotherapy and radiotherapy without major surgery being done solely for the diagnostic purposes.1,2 This study of unguided transthoracic fine needle aspiration determines that it is an easy and convenient diagnostic modality which can be performed rapidly with low risk. As shown from the present study, it provided a definitive diagnosis in $66 \%$ of the cases at low cost with minimal complications. Since all the cases were unguided and randomly selected irrespective of size this may be the reason for low diagnostic yield in our study in comparison to other studies from India. ${ }^{1}$ The other causes of negative aspirates were fibrotic lesions, diffuse lesions, association with pleural effusion and tumour with collapse of lung. Malignancies may produce inflammation or pneumonia secondarily, the aspiration of which gives the impression of an inflammatory lesion. Squamous cell carcinomas may present clinically and on aspiration as acute abscess. Foreign body giant cells and histiocytes are often present at the periphery of lung cancers, particularly squamous cell carcinomas, as a reaction to tumour necrosis. In squamous cell carcinoma and 
small cell carcinoma, the tissue necrosis is very prominent. These cases are not classified as malignant unless well preserved carcinoma cells are seen. Reactive lymphocytes can sometimes be confused with small cell carcinoma cells. A correlation with clinical history and radiological findings will prevent some of the pitfalls associated with the technique. There are other few studies where the diagnostic yield was between $58 \%-72 \%$ similar to our study. In comparative studies, this technique has generally been reported to be superior to bronchoscopic biopsy and sputum cytology in the diagnosis of radiologically evident lung lesions particularly in lung cancer patients. Metastatic lesions and lymphomas do not regularly shed cells into sputum, but when aspirated produce diagnostic cellular material. 4,5

However, in our series, we had a variety of cases as shown in Table 1. The most common malignancy in our study was squamous cell carcinoma followed by adenocarcinoma, which was in concordance with other studies.6,7 The other cases encountered were small cell carcinoma, poorly differentiated carcinoma, large cell \& bronchoalveolar carcinoma. We also encountered a rare case of adenosquamous carcinoma of the lung in our study. Among the secondary lesions we found a case of extra skeletal Ewing's sarcoma, the primary of which was soft tissue swelling in the right thigh. Bone was uninvolved by the X-ray study. Ewing's sarcoma, which is a small round cell tumour can be mistaken for small cell lung carcinoma. However, the small cell carcinoma was ruled out because of the presence of two types of cells- small \& large, absence of nuclear crush artefacts and nuclear moulding.

Fine needle aspiration can be used for diagnosis of nonneoplastic condition such as tuberculosis \& other inflammatory conditions. Diagnosis of tuberculosis on FNAC will lead to early initiation of antitubercular drugs in these patient \& thus help in better health care.

Our series demonstrated very high sensitivity and specificity in the diagnosis comparable to other studies.6, 7, 8 However, skill and experience of the pulmonologist and pathologist are important for achieving satisfactory results. With the advent of higher resolution imaging techniques, it is made possible to pass a needle into any mass, even if it is small and deep seated. ${ }^{9}$ However, unguided FNA can be useful in the peripheral health care setup.

\section{CONCLUSION}

Percutaneous transthoracic FNAC, which was introduced for the diagnosis of microbial organisms causing lung lesions is now used for the diagnosis of any undiagnosed pulmonary lesion- solitary and diffuse infiltrative. This study has demonstrated the usefulness of the unguided TFNAC for diagnosis not only for neoplastic lesion but also the nonneoplastic intrathoracic lesions. Though it is apparently a step backward, it has got merits, being a rapid, safe, accurate, cost effective procedure for the diagnosis of intrathoracic lesions and also can be used as an effective outdoor procedure even in peripheral health centres in developing countries like India in properly selected cases.

\section{REFERENCES}

[1] Prasad R, Kushwaha RAS, Mukherjee PK, et al. Accuracy and safety of unguided transthoracic fine Needle aspiration biopsy in the diagnosis of intrathoracic lesions. Ind J Tub 1994;41:167-70.

[2] Sharma SK, Verma K, Pande JN, et al. Fine needle aspiration biopsy cytology for diagnosis of intrathoracic lesions. Indian J Chest Dis Allied Sci 1983;25:41-5.

[3] Suri JC, Goel A, Bhatia A. Safety and efficacy of unguided trans thoracic fine needle aspiration biopsy (FNAB) in outdoor patients. Indian J Chest Dis Allied Sci 1991;33(3):129-32.

[4] Nasiell M. Diagnosis of lung cancer by aspiration biopsy and a comparison between this method and exfoliative cytology. Acta Cytol 1967;11(2):114-9.

[5] Walls WJ, Thornbury JR, Naylor B. Pulmonary needle aspiration biopsy in the diagnosis of Pancoast tumors. Radiology 1974;111(1):99-102.

[6] Crosby JH, Hager B, Høeg K. Transthoracic fine-needle aspiration. Experience in a cancer center. Cancer 1985;56(10):2504-7.

[7] Khouri NF, Stitik FP, Erozan YS, et al. Transthoracic needle aspiration biopsy of benign and malignant lung lesions. AJR Am J Roentgenol 1985;144(2):281-8.

[8] Cristallini EG, Ascani S, Farabi R, et al. Fine needle aspiration biopsy in the diagnosis of intrathoracic masses. Acta Cytol 1992;36(3):416-22.

[9] Dash BK, Tripathy SK. Comparison of accuracy and safety of computed tomography guided and unguided transthoracic fine needle aspiration biopsy in diagnosis of lung lesions. J Assoc Physicians India 2001;49:626-9. 